\section{Obstetric Traces}

As a result of pregnancy the pelvic bones undergo changes which are permanent or fade only in old age. Apart from the forensic use of this knowledge, it throws light on archaic populations. Angel ${ }^{1}$ pioneered this approach in Greece and Anatolia, his chief concern being to assess fecundity, generation length, and rates of population increase. This work was based on changes in the pubic bone. Recently, it has been applied to solve specific obstetric problems in ancient skeletons. ${ }^{2}$

Philip Houghton ${ }^{3}{ }^{4}$ has emphasized that alterations of the iliac preauricular groove are even commoner and more extensive than those of the pubis, and he demonstrates this in a series of prehistoric Polynesian skeletons. These pelvic changes, he believes, are the only conclusive skeletal evidence of sex. This opinion needs confirmation, for many skeletons have features of such extreme masculinity that even the most android of women could hardly be supposed to exhibit them. It is also likely that, on rare occasions, "pregnancy" changes are found in male pelves as a result of unusual stresses on the relevant ligaments.

A most useful tool for the palaeodemographer would be to know how many children a woman had borne. Unfortunately this can be estimated only approximately, for the bone changes are diverse, and it is clear that the alterations which occur vary with the nature of the labour itself and also the puerperium. This has been dramatically shown by Cockshott ${ }^{5}$ in a series of 312 Nigerian women with obstetric vesicovaginal fistulae. A further difficulty, for the palaeopathologist if not for his forensic colleague, is that in archaic cemeteries the pubic bones especially, and to a less extent the preauricular area, often disintegrate badly because of soil erosion. In a series of Early Saxon burials it was possible to identify pregnancy changes in only 20 out of more than 700 inhumations. $^{6}$

1 Angel, J. L., American fournal of Physical Anthropology, 1969, 30, 427.

2 Hawkes, S., and Wells, C., Medical and Biological Illustration, 1975, 25, 47.

${ }^{3}$ Houghton, P., American fournal of Physical Anthropology, 1974, 41, 381.

${ }^{4}$ Houghton, P., Bulletin of the New York Academy of Medicine, 1975, 51, 655.

5 Cockshott, W. P., Clinical Radiology, 1973, 24, 241.

6 Wells, C., unpublished information.

\section{Stereotaxic Neurosurgery for Cerebral Palsy}

Stereotaxic operations on the brain were introduced in 1947 by Siegfried and colleagues, ${ }^{1}$ and their technique was soon applied to patients with cerebral palsy. By 1960 Narabayashi and his colleagues ${ }^{2}$ reported encouraging results in cases of athetoid cerebral palsy, and stereotaxic ablation of the cerebellar dentate nucleus has been shown to give relief in some cases. ${ }^{34}$

Gornall and colleagues ${ }^{5}$ have recently reported their own results in 10 children on whom stereotaxic surgery was performed. The procedures were either thalamotomy or dentatotomy. Their patients ranged in age from $2 \frac{1}{2}$ to $11 \frac{1}{2}$ years at the time of first operation, and seven of them presented mainly with disorders of gait or the use of their hands. All had had extensive physiotherapy treatment and often orthopaedic surgery before stereotaxic surgery was applied. Most were active and alert, were thought to be of normal intelligence, and appeared to be co-operative. Two patients were referred for stereotaxic surgery because of the nursing problems from quadriplegic cerebral palsy. One of these had prolonged neonatal jaundice after a difficult birth, and the other had sustained a severe head injury. The latter two children comprehended language but were unable to speak.

Thalamotomy on the contralateral thalamus or dentatotomy on the ipsilateral dentate nucleus were performed under general anaesthetic after contrast venticulography through a parietal burr hole to establish the correct anatomical relationship. Though complications were encountered in 5 of the 10 patients, they neither lasted long nor affected the final result. After thalamotomy one patient deteriorated while four improved, and after dentatotomy five improved and one remained unchanged. The authors stress that stereotaxic surgery in relation to spasticity and to cerebral palsy is not an end in itself but may help in the overall management. The continuation of physiotherapy and orthopaedic surgical aftercare is essential.

While stereotaxic surgery has won a place in the management of adults with spastic lesions secondary to brain damage, the need for it in children has not been widely accepted. One reason for this is that in adults the operation can be performed under local analgesic, so that the effects of a trial injection into a cerebral nucleus can be assessed before permanent destruction

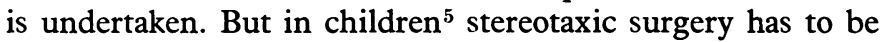
performed under general anaesthetic, so that accurate localization is impossible. For this reason it is unlikely that it will be widely undertaken on children with cerebral palsy.

\footnotetext{
1 Siegfried, J., et al., Confinia Neurologica, 1970, 32, 1.

2 Narabayashi, H., Confinia Neurologica, 1962, 22, 364.

3 Heimburger, R. F., Confinia Neurologica, 1969, 31, 57.

4 Krayenbuhl, H., and Siegfried, J., Confinia Neurologica, 1972, 34, 29.

${ }^{5}$ Gornall, P., Hitchcock, E., and Kirkland, I. S., Developmental Medicine and Child Neurology, 1975, 17, 279.
}

\section{Pregnancy in Adolescence}

The briefest glimpse of the journals shows that adolescent or teenage pregnancy is now a worldwide problem. There are papers on the subject from America, ${ }^{1}$ Venezuela, ${ }^{2}$ and Nigeria. ${ }^{3}$ The first of these compares 100 girls under 20 who chose to deliver their babies, 100 who chose abortion, and 50 who had experienced intercourse but had never been pregnant. They were all from Brooklyn, and $80 \%$ were Black and $10 \%$ were of Spanish extraction. The findings of the study were scarcely dramatic, inured as we have become to similar findings almost everywhere. For instance, of the two major groups 69 and $73 \%$ had not used any form of contraception. Otherwise the condom was the most frequently used protective. In $50 \%$ of the cases the mother of the adolescent was the head of the household; $30 \%$ of the teenagers choosing to deliver their babies had not completed elementary schooling.

So there is the same sorry tale of broken homes, breakdown of family life, and poor education, as well as the failure of education about contraceptives to reach those most in need of it-or at least the failure to make the teenagers use the knowledge they have. Perhaps we can only scratch our heads and vaguely feel that there is something wrong with society.

Society seems unable to heal itself, so it is left to medicine to help as best it may to mitigate the worst effects of adolescent 